\title{
How to Create a Religion
}

\author{
E. Thomas Lawson \\ Western Michigan University
}

\begin{abstract}
The aim of this paper is to suggest that it is worthwhile seeing what the various studies in the cognitive science of religion have taught us by engaging in a thought experiment in which we ask: "What would it take to create a religion on the basis of what we think that we now know about religiosity?" It will be an exercise in applied science by following a set of instructions.
\end{abstract}

\section{Keywords}

conceptual scheme, cognitive science of religion, action representation, counter-intuitive agent, ritual

\section{Contact address}

E. Thomas Lawson, Professor Emeritus, African Religions. Department of Comparative Religion, Western Michigan University, 1903 W Michigan Ave, Kalamazoo MI 49008-5320 USA

There can no longer be any doubt that the cognitive (and evolutionary) science of religion, CSR, is a vibrant and progressive research program with participants from a wide range of disciplines and from many parts of the world. Theoretical, empirical and experimental work proceeds apace. Many issues are being addressed in conferences, books and in scientific journals. Some of the most interesting have been projects focused upon issues such as 1) whether particular religious notions are by-products or adaptations, 2) the distinction between theological correctness and intuitive notions, 3) the role that counter-intuitive notions play in cultural transmission, 4) the importance of notions of biological and psychological death and the role such notions play in after-life beliefs, 5) credibility enhancing displays, 6) the utility of the distinction between transmitted and evoked culture, 7) costly signaling, 8) the role that "Big Gods" play in the evolution of religious systems and so on. Some of this work has been examined carefully in books such as Martin and 
Wiebe's Religion Explained? The Cognitive Science of Religion After Twenty-five Years. ${ }^{I}$ The aim of this paper is to suggest that it is worthwhile seeing what these studies have taught us by engaging in a thought experiment in which we ask: "What would it take to create a religion on the basis of what we think that we now know about religiosity?"

I was inspired to attempt this task after having read Richard P. Feynman's Six Easy Pieces: Essentials of Physics Explained ${ }^{2}$ a work in which he throws out the following challenge: "If you can't build it you don't understand it!"

Let us, therefore imagine a situation in which I am asked the question "So, what instructions would you give a person who wishes to consciously create a religion that at least has some chance of succeeding?"

First, I would argue that you need something for people to think about. This means that you will need a set of ideas set within the framework of a story. Let us call this framework the conceptual scheme. This conceptual scheme should consist of a set of agents as well as narratives, oral or written, that will play a specific part in the actions that the agents are engaged in, and also a set of one or more experiences which involves some change in status as a consequence of the actions of the agents. At least one of the agents in the conceptual scheme will have to possess some minimally counter-intuitive qualities that will set this agent apart from all of the other agents described by the conceptual scheme.

The second requirement in this creative process is that the agents in the story need something to think about but something to do. Let us, therefore, prescribe a set of actions that have some relation to the set of ideas in the conceptual scheme. Let us call this the "action representation system". This system will have a very simple structure: somebody does something to someone by means of an instrument of some kind. This structure should not be confused with another structure, i.e., somebody does something. What is the difference? Well, you can do something without doing something to somebody! You can, for example, whistle, laugh, sing, pray, dance, or just think without such actions being done to somebody or something. We will find out, in due course, why this is an important distinction but at this point let me just say that religiosity can involve actions that do not bring about a change in status. On the other hand, some of the most important actions in any religion do so whether we are talking about what Whitehouse ${ }^{3}$ has called imagistic and doctrinal religions. We have here two structures to employ in our creation of a religion. In one case we have an agent doing something such as chanting, (Agent-action) and in the other an agent doing something to someone or something by means of an instrument (agent-action-patient-instrument), such as when an agent touches a patient (the recipient of the action) with a stick.

\footnotetext{
${ }^{1}$ Luther Martin, and Donald Wiebe, Religion Explained? The Cognitive Science of Religion After Twenty-Five Years, (London and New York: Bloomsbury Publishing, 2017).

${ }^{2}$ Richard P. Feynman, Six Easy Pieces: Essentials of Physics Explained by its most Brilliant Teacher, (New York: Perseus Books, 1994).

${ }^{3}$ Harvey Whitehouse, Modes of Religiosity: A Cognitive Theory of Religious Transmission, (Oxford: Altamira Press, 2004).
} 
In the first case the chanting is something in this particular religious context which one typically does in particular situations, for example at various points in a religious service. In the second case being touched by a stick would signify that the recipient of the action has a new status "having been touched by a stick." (Think, for example, of someone having been knighted by the Queen by means of being touched by a sword).

But now we also begin to see why you should expect there to be at least one agent that needs a special (counter-intuitive) quality because not just anybody can bring about a change of status simply by touching someone else by an instrument of some kind. The agent must be qualified to bring about the change, and I suppose the instrument had better be qualified as well. In a particular system of knighthood only the regent can confer knighthood.

How does the qualification come about? I can think of three ways: by inheritance. "I am qualified to bring about the change of status because I inherited the quality from my ancestors." Or I can do so by being made qualified by a person already qualified who makes me qualified by means of a special action involving an instrument of some kind. "I was touched by an instrument with special qualities which was made special by an agent with special qualities", or by a special experience which my followers are willing to attribute to me, or credit me as having. "I experienced a special feeling unlike any other kind of feeling and that makes it possible for me to bring about a change of status in someone else." I am sure the reader can easily find illustrations of all three forms of "qualification" in particular religious traditions, ethnographic reports, or historical accounts of religious practices. In any case in the religion we are creating qualification is an important component in the conceptual scheme and in the action representation system.

Having established the structure of the action that distinguishes between kinds of actions and having highlighted those that bring about some kind of change of status, it is important to recognize that these sets of actions will have to be connected to one another in quite specific ways. Let us take an easy example. In order to become a member of a particular religion one has to undergo the act of being initiated into the community either by being, for example, immersed in water or being sprinkled by water. As we have already seen, the agent performing the initiation must be qualified to do so. In order to be qualified, the agent performing the initiation has to have already been initiated. In this religion initiation is a necessary condition for being able to initiate someone. It is not, however, a sufficient condition because the agent will also have to have been initiated in order to be initiated, which is another special set of actions. In fact, that process or chain of actions is only conceived of as having been stopped by the originator of the entire process a CIagent! So in creating a religion one would have to have an entry "ritual" or set of actions, and one or more sets of qualification actions to make the whole system work. You most probably will also need to have a "leaving" or even an "expulsion" ritual.

There is, however, much more to do. One will find that while some actions will be done frequently, others will only be done occasionally. If you only have one ritual, then frequent repetition will lead to boredom. So you had better have more than one. In fact, it might make sense to have two kinds of rituals, the first kind to do frequently to keep 
one focused and identified with the community, the second one to be done infrequently so that it can be seen as being a special event. Underlying this requirement is the idea that it is important to make some of the actions in this religion memorable and worth celebrating or at least distinguishing them from all of the other actions in the religion. The most memorable ones are those that are only done once, the least memorable because they are almost automatic, are those done most frequently. Now let us connect the most memorable ones with the CI-Agent either directly or indirectly performing the set of actions upon the initiate, whereas the most frequent ones have the initiate performing the set of actions upon the CI-Agent. In the first case, the CI-Agent does the action either directly or through an intermediary, while in the second, the receiver of the action, the patient, does the action to the CI-Agent. In our design I would argue that it is better to have both kinds rather than just one or the other, i.e. unique versus repetitive rituals. If you only have a unique ritual then there is something to look back upon, there is nothing to look forward to, whereas if you only have repetitive actions there is nothing to look either back to or forward to because it is simply boring, "the same old same old!" Unique events grab our attention, repetitive acts lead to habituation. What we see in these two kinds of rituals is that unique rituals focus upon the qualities of the agent, the initiator of the action, whereas in the repetitive rituals the focus is on the qualities of the recipient. The best way to achieve memorability and, therefore, the persistence of our religion is to enhance memorability by raising the emotions. And the best way to raise the emotions is by encouraging sensory pageantry. So in our religion we will have occasional festivals, powerful initiations and day to day simple acts to remind us that we belong to a religion.

Apart from the qualities of the initiator and the initiated, it is also worth specifying the actions themselves especially when those actions themselves should have an extraordinary property that distinguishes them from ordinary actions, for example, washing oneself when one is already clean, wearing special clothes when one already has sufficient clothing, butchering an animal not for eating but for classifying relationships and so on. This is known as goal demotion where the typical purpose is distinguishable from its ritual purpose. (Boyer and Lienard 2006). The ritual purpose can be explicit, that is to say, the conceptual scheme can give the ritual scenario specific content. That kind of knowledge is usually the consequence of conscious reflection. It is the kind of knowledge that the participants will suggest if questioned about what and why there are doing such things. But it is not the only reason. There might be very well a much deeper and unconscious reason why people are motivated to perform certain kinds of puzzling actions. They feel the necessity to do them but do not really know why. So you can get answers like: We do it because it is the custom, or we do it because other people do it, or, don't ask me, ask that person instead. It is worthwhile, therefore, to examine the conditions under which such acts are performed. And this is where evolutionary psychology provides us with important clues. All organisms, and certainly all humans, face situations when they are face with threats to well-being, for example, predation and assault, contagion, loss of status and diminution 
of resources. ${ }^{4}$ Such anxiety-causing threats can be immediate or potential. Responses to immediate threats create fear and the typical responses are freezing, fleeing of fighting. But what we have learned from precautionary psychology ${ }^{5}$ is that humans are also attuned to potential threats. Such a capacity leads to devising strategies to attempt to ensure safety. I would expect humans to develop forms of behavior (rituals) to reflect such concerns. In the case of predation and assault, I would expect rituals to reflect strategies that suggest ways to find power to avoid predation and resist assault. In the case of contagion and pollution, I would expect rituals to reflect notion of prevention for example by ritual washing or ingesting palliative substances or acts of cleansing caused by pollution. In the case of loss of status I would expect the establishing of new forms of status by ritual means. And in the case of loss of resources I would expect rituals in which a loss of one sort is replaced by gaining resources of a different kind (maybe symbolic?). It certainly is the case when looking at actual rituals how we end up finding the very themes that we would expect to find in rituals. Themes that echo the threats and the solution to threats, for example, ritual washing when already clean. ${ }^{6}$

It will also be important to weigh the costs and benefits of the new religion. In the real world an action has costs. This is just as true in a religious world because religious notions employ the same ordinary cognitive processes. ${ }^{7}$ In light of the various requirements listed above it is clear that costs in time, energy, assets and establishing social relationships will be present. But there will also be benefits that contribute to fitness, namely, modes of signaling commitment to the religious system, the means of showing group identity, and clear markers of out-group delineation.

If we want this religion to succeed It will also be important for it to be balanced. ${ }^{8}$ Balanced involves a number of factors. Dissension in a religion, even a newly created one, is inevitable. An important way to overcome dissension is by achieving conceptual control. Maintaining complexity tends to ensure conceptual control over the system. Conceptual control can be maintained by 1) instituting a hierarchy with entry into any particular level only under special conditions, 2) distinguishing between ritual practitioners and ritual participants, 3)ensuring that the practitioners have a special status (e.g. a priest), 4) requiring acquisition of special status by means of ritual transition as a patient (i.e. as the recipient of the action), 4) distinguishing between insiders and outsiders and permitting outsiders limited means of participation and 5) having both frequent and infrequent rituals.

\footnotetext{
${ }^{4}$ Pascal Boyer and Pierre Lienard, (2006) "Why ritualized behavior? Precaution system=mw and action parsing in developmental, pathological and cultural rituals?”, Behavioral and Brain Sciences 29 (6) (2006): 595-650. ${ }^{5}$ H. Szechtman and E. Woody, (2004) "Obsessive Compulsive Disorder as a Disturbance of the SecurityMotivation System”, Psychological Review 111(1) (2004): 111-127.

${ }^{6}$ Pierre Lienard and E. Thomas Lawson, "Evoked Culture, Ritualization and Religious Rituals", Religion 38 (2O) (2008): 157-171.

${ }^{7}$ E. Thomas Lawson and Robert N. McCauley, Rethinking Religion: Connecting Cognition and Culture, (Cambridge: Cambridge University Press, 1990).

${ }^{8}$ Robert N. McCauley and E. Thomas Lawson, Bringing Ritual to Mind: Psychological Foundations of Cultural Forms, (Cambridge: Cambridge University Press, 2002).
} 
The history of religions shows dissension can never be eliminated but it can and has been controlled. While charismatic figures will play an important role in a developing religion, the balance of the system itself is as important as the originating charismatic figure. In fact some charismatic figures are very short-lived because they failed to intuit the importance of a balanced system. The path to creating a new religion is littered with the bones of charismatic figures who were unable to overcome their own narcissism.

Here my thought experiment ends. I am certain that what I have presented is not the only way that an actual religion, whether imagistic or doctrinal (to use Whitehouse's terms), is formed over time, but I do think that it provides a kind of template or heuristic by means of which we can examine the kinds of data that historians and ethnographers provide us with in their hard work. These researchers are constantly encountering examples of strange substances or even acts regarded as "polluting", odd practices such as shunning or demanding a change of status of someone hierarchically higher, or attitudes to outsiders as infidels, heathen or sinners. What I have tried to show is that such acts, practices or attitudes should be expected in the scientific adventure involved in the attempt to explain various forms of human behavior.

\section{Bibliography}

Boyer, P and Lienard, P. (2006), Why ritualized behavior? Precaution system $=\mathrm{mw}$ and action parsing in developmental, pathological and cultural rituals? Behavioral and Brain Sciences 29(6) 595-650.

Feynman, R. (1994), Six Easy Pieces: Essentials of Physics Explained by its Most Brilliant Teacher, Perseus Books. Lawson, E. T. and McCauley, R. N. (1990), Rethinking Religion: Connecting Cognition and Culture, Cambridge: Cambridge University Press.

Lienard, P and Lawson, E. T. (2008), Evoked Culture, Ritualization and Religious Rituals, Religion 38(2O) 157-171.

McCauley, R. N. and Lawson, E. T. (2002), Bringing Ritual to Mind: Psychological Foundations of Cultural Forms, Cambridge: Cambridge University Press.

Martin, L and Wiebe, D. (2017), Religion Explained? The Cognitive Science of Religion After Twenty-Five Years, Bloomsbury.

Whitehouse, H (2004), Modes of Religiosity: A Cognitive Theory of Religious Transmission, Altamira Press.

Szechtman, H and Woody, E (2004), Obsessive Compulsive Disorder as a Disturbance of the SecurityMotivation System, Psychological Review 111(1) 111-127. 